\title{
THE SENSITIVITY OF A PHOTOGRAMMETRIC METHOD IN FORMABILITY ANALYSIS
}

\author{
Ján SLOTA*, Miroslav JURČIŠIN*, Ivan GAJDOŠ*, Emil SPIŠÁK* \\ *Faculty of Mechanical Engineering, Department of Technologies And Materials, Technical University of Košice, \\ Letná 9, 04200 Košice, Slovakia \\ Jan.Slota@tuke.sk, Miroslav.Jurcisin@tuke.sk,Ivan.Gajdos@tuke.sk, Emil.Spisak@tuke.sk
}

\begin{abstract}
Nowadays is a possible to implement numerical simulation and photogrammetric inspection to the complex process chain of inspection. In the recent years there has been significant progress in accuracy improving of these methods of inspection in pre-production or post-production stage of manufacturing. This article discusses these two methods from sensitivity and comparison point of view. Most attention has been paid to the photogrammetric method and his sensitivity to using different approaches. Results were compared with the result of numerical simulation and experiment. Numerical simulation was performed in static implicit finite element code Autoform. For this purpose, GPS cover of galvanized steel of DQ category was used for inspection. In this paper was proved that photogrammetric method of strain measurement is highly sensitive on the various external factors. Further results and findings are included in the next chapters of this paper.
\end{abstract}

Key words: Photogrammetric Method, Strain Measurement, Deep Drawing, Simulation

\section{INTRODUCTION}

Numerical simulation and optical photogrammetric methods are nowadays frequently used inspection tools of manufacturing process. This is evidenced by the amount of scientific articles and conferences aimed to this problematic all over the world that dealt with use of these methods in the various fields of manufacturing. For example exploitation in the analysis of optimisation of forming process of drawnpiece (Fracz et al., 2013), health care services (Goellner et al., 2010), validation process of sheet metal materials of case study, in Audi corporation (Griesbach, 2010), in the analyses of draping cracks in the glass fiber textile industry (Kruse and Wendland, 2010), analyses of deep drawing process of GPS cover (Slota and Jurčišin, 2010) and many others applications. Photogrammetric measurement of strain works on the method of digital image correlation (DIC), and several publications were devoted to the detailed description of the DIC method. For example in the analyses of monitoring crack growth using videoextensometry techniques (Ambriško and Pešek, 2011), videoextensometric monitoring of various deformation characteristics in a static tension loading (Hlebová et al., 2011) or photogrammetric monitoring of deformation process using different strain rates (Mihaliková et al., 2011). In this paper, photogrammetric measuring was performed using ARGUS system. ARGUS is the contactless measuring system that on the basis of optical scanning allows predicting critic areas which are taking places during forming process. On the sheet metal is before forming applied grid of circle points. Size of these points is obviously between 1 and 6 $\mathrm{mm}$. Grid is deformed at the same time as the sheet metal is deformed. Grid of circle points is by the influence of direction and intensity of stresses deformed, and is changing his shape. Measuring consists on the photogrammetric principle where surface is scanned using CCD camera with high resolution. Pictures are taken from different angles, and with using of image processing are computed $3 \mathrm{D}$ coordinates of grid points. Distances between points of grid are defined by lateral distortion. On the basis of law of volume preservation are computed decompositions of major and minor strains, thickness reduction or critical areas of drawn part, etc. (ARGUS User Guide, 2011). Digital image correlation method and numerical simulation of deep drawing process is useless, if the results are not corresponding with results of experimental measuring. Therefore is necessary to investigate difficulties associated with new progressive methods of inspection. In this paper was investigated GPS cover. Five different depths of drawn part were inspected. Results were compared with results of experimental measuring. Process was modeled in static implicit simulation software Autoform. Autoform is simulation software which is developed in cooperation with many world known companies as for example Audi, Arcelor, ThyssenKrup but also by HP whether IBM (Cover story: Focus on CAD CAM and simulation, 2011). As was mentioned, software works with implicit time integration strategy which is in every time step starting from the previous time step and a mesh is generated using local refinement due to requiring accuracy of problem, which is calculated resulting from current mesh. This solving process is iterated until the estimated error is between bounds of the interval of requiring precision. If the time step between new iteration is not too large, the time of solving process is usually very small (Schmidt and Kunibert, 2004).

\section{EXPERIMENTAL PROCEDURE}

The aim of this experiment was to investigate difficulties which were observed during the inspection of part using photogrammetric measuring method. For this purpose was used ARGUS measuring system which is type $12 \mathrm{M}$, with resolution of camera 12 million pixels in case of photo camera and system $5 \mathrm{M}$ with 5 million pixel resolution in the case of video camera. Diameter of points etched on sheet was $1 \mathrm{~mm}$. Distance between their centers was $2 \mathrm{~mm}$, but measuring was possible also in the middle points 
of grid, it means that measurement was performed in the minimal step distance about $1 \mathrm{~mm}$. The accuracy of the ARGUS system within strain measurement is up to $0.2 \%$ [9]. Mechanical properties of the drawn part made of mild steel DX $52 \mathrm{D}$ are in the Tab. 1. Thickness of the blank was $0.5 \mathrm{~mm}$. Initial shape of the blank, with etched grid is illustrated in the Fig. 1. Dimensions highlighted in the Fig. 1 are a x b with values $44 \times 160 \mathrm{~mm}$, respectively.

Tab. 1. Mechanical properties of investigated steel

\begin{tabular}{|c|c|c|c|c|c|}
\hline Steel & $\mathbf{R}_{\mathrm{e}}[\mathrm{MPa}]$ & $\mathbf{R}_{\mathrm{m}}[\mathrm{MPa}]$ & $\mathbf{A}_{\mathrm{g}}[\%]$ & $\mathbf{C}[\mathrm{MPa}]$ & $\mathbf{n}[-]$ \\
\hline DC 52 D & 264 & 360.5 & 15.9 & 568 & 0.13 \\
\hline
\end{tabular}

The grid of points was etched by electrochemical method using electrolyte which is suitable to the zinc coated surface of sheet. Special anti-reflexive spray was available as a last option in order to avoid inaccuracies related to the reflexive effect, because it can influence measurement in terms of strain amount. Illustration of image in ARGUS measurement is illustrated in the Fig. 2. Blue colour of element represents elements which are detected and rendered. Empty place represents place which is insufficiently recorded and therefore is necessary another photo from different angle. To compensate optical distortion and better locate all reference points the picture calibration was used.
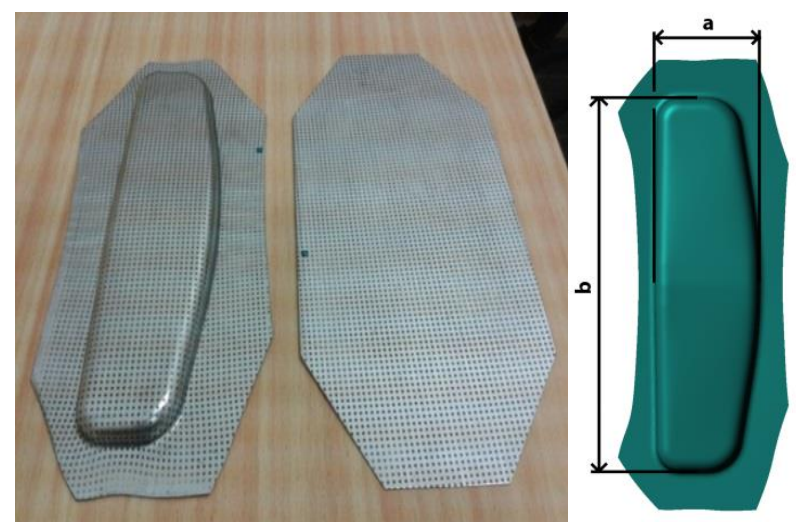

Fig. 1. Final shape and dimensions of the part and the blank

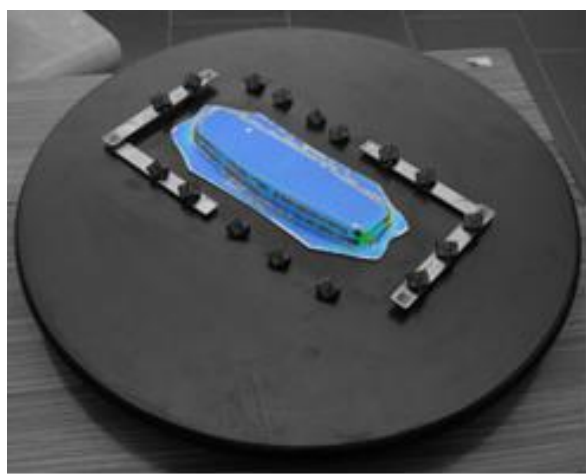

Fig. 2. Photogrammetric strain measurement in ARGUS using video camera

Drawing process was performed in the hydraulic press ZD 40. In order to minimalize friction, teflon film was used. This experiment had several objectives. First objective was to etch grid of points on 7 blanks illustrated in the Fig. 1 right, measure strains by photogrammetric method and compare results of measuring considering the shape of part and amount of major strains. Best 5 blanks were subsequently used for the deep drawing process and again inspected with ARGUS system where thickness reduction was measured and compared with results of numerical simulation and experimental measurement. Next objective was to quantify difference between scanned results of blank with and without antireflexive spray. For better illustration, difference between surface of sheet with and without the anti-reflexive spray is illustrated in the Fig. 3. Last objective was to identify differences between results of the measuring using photo camera and video camera.

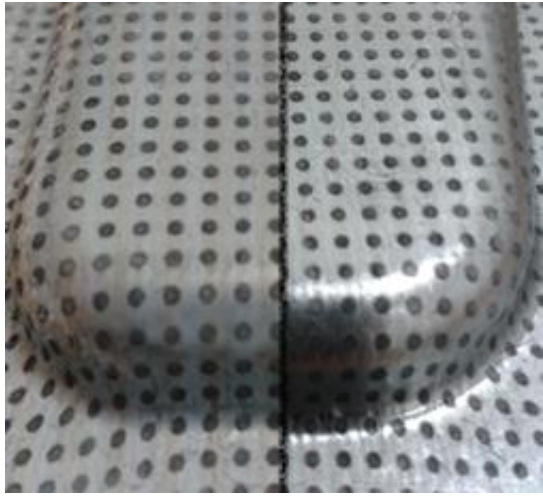

Fig. 3. Area with developer (on the left) and without developer

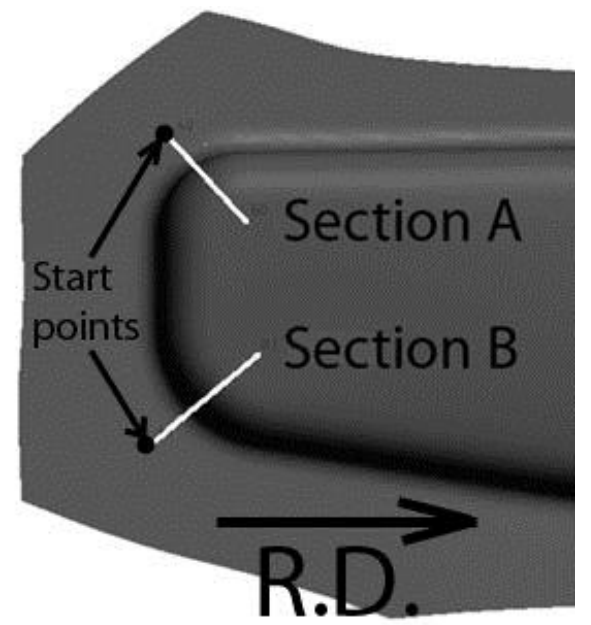

Fig. 4. Sections on the drawn part with highlighted sections, start points of measuring process and rolling direction

As was mentioned, deep drawing process was modelled in the static implicit code Autoform. This code is discretizing blank by triangular mesh. For better precision, element size was set to 1 $\mathrm{mm}$. Number of integration point was automatically set to the value 11 . This value is automatically set as soon as springback computation is required. Angle of triangular element was set to the value $22.5^{\circ}$. Maximum level of refinement was set to the value 4 . Implies from this, minimal element size in places where was sheet maximally deformed was $0.0625 \mathrm{~mm}$. Such small refinement was not localized on the final shape of part after simulation. Shell elements were used in process of numerical simulation. Hardening curve was defined using approximation function which is available in Autoform code and Hill's 48 yield criterion was defined with defining $R_{e}$ and $r$ values in directions 0,45 and $90^{\circ}$ 
to the rolling direction. These values were $1.28,0.89$ and 1.71 respectively. Coefficient of friction was set to the value 0.15 and the gap between punch and die was equal to the thickness of the sheet except for the critical places on the radii where the gap was increased about the value of $10 \%$ of the sheet. Comparisons of results obtained from experimental, numerical and photogrammetrical measuring were investigated in two sections of part curvature, which are illustrated in the Fig. 4. These two part curvatures were selected due to existence of the most critical strain and stresses in these areas. Experimental data were obtained in the 8 selected local places of curvatures.

\section{RESULTS AND DISSCUSSION}

Results of measurement differences between two cases with and without anti-reflexive spray will be discussed as first. Shape of scanned blank and value of major strain is considered. Since the sheet is so far not loaded by any force, expected value of major strain is 0 . However, as experiment shown, by the inaccuracies of scanning or etching, value of major strain is not equal to zero. Also is observed small difference between shape of the same surface of blank with and without anti-reflexive spray. Result is illustrated in the Fig. 5.
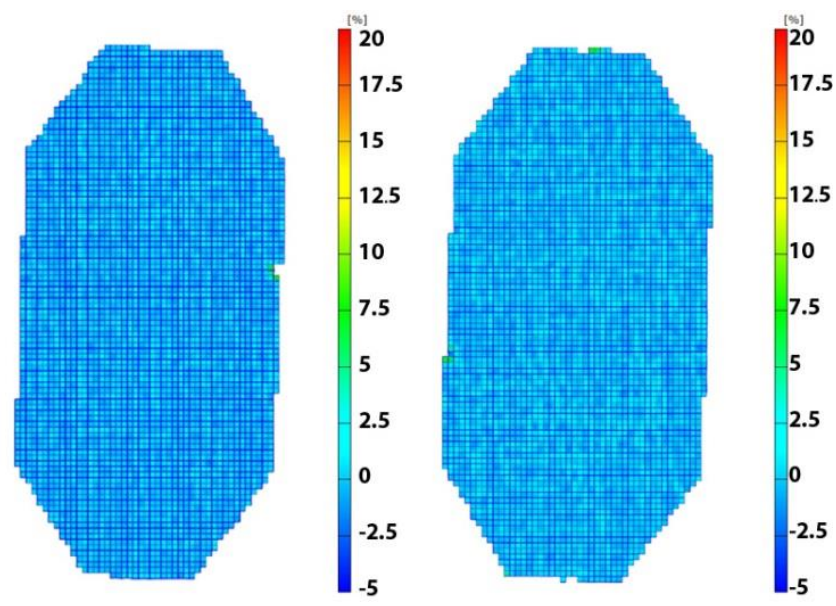

Fig. 5. Results of scanning by ARGUS. On the left side is scanned blank with anti-reflexive spray and on the right side is scanned blank without the anti-reflexive spray

Tab. 2. Influence of anti-reflexive spray

\begin{tabular}{|c|c|c|}
\hline Parameter & With spray & Without spray \\
\hline Max. MS [\%] & 7.93 & 8.25 \\
\hline Min. MS [\%] & -3.49 & -1.66 \\
\hline Average of MS [\%] & 0.62 & 0.48 \\
\hline Standard deviation of MS [\%] & 0.54 & 0.62 \\
\hline Difference [\%] & \multicolumn{2}{|c|}{29.2} \\
\hline
\end{tabular}

First of all as can be seen, on the sheet are measured positive and negative values of major strain (MS) before forming. This may be caused by several errors which will be described in further experimental result. In this case is experiment directed to the influence of anti-reflexive spray. Shape of blank is almost the same in both cases, but there is difference in measured values of strain. In sprayless case is measured maximum major strain of value $8.25 \%$ and in the other case is maximal in the same place $7.93 \%$. Greater difference in the minimal value of major strains in case without spray $(-3.49 \%)$ and with spray $(-1.66 \%)$ occurred. It was computed, that in case with spray was arithmetic value of major strain in longitudinal section $0.62 \%$ and standard deviation $0.54 \%$ and in the case without spray was arithmetic value of major strain $0.48 \%$ with standard deviation $0.62 \%$. For better understanding, results are illustrated in the Tab. 2 .

Difference is calculated using following equation:

$d=\frac{M S_{S}-M S_{W S}}{M S_{W S}}$

where: $d$ - difference, MSs - Average of major strain with the application of anti-reflexive spray, MSws - average of major strain without the application of anti-reflexive spray.

From results in Tab. 2 implies, that when anti-reflexive spray is used, value of major strain in this case is higher about $29.2 \%$. Differences could be caused by the small change of circle diameters after layer of anti-reflexive spray was applied. However, when the spray was used, smaller standard deviation of results occurred. It means that points showed a higher degree of uniformity. Local places where major strain reached value up to $8 \%$ may be etched incorrectly - for example, time of etching was exceeded or surface of sheet was affected by the various undesirable substances. Since the value of major strain measured by ARGUS is higher using anti-reflexive spray, it should be used only in cases where it is necessary, so in cases where the surface of sheet is highly reflective.

On all blanks in pre-production phase was etched grid of points in order to perform measuring which will illustrate various inaccuracies of etching and measuring. It is considered that the value of major strain on the sheet before forming is equal to zero. Results of measuring showed, that reality is different. First, as is illustrated in the Fig. 6 and 7, empty places on the blank are observed and also different distribution of major strain is observed. From illustrated results implies, that not all blanks were scanned sufficiently enough. Especially on samples marked as 3 and 6 are visible empty places, where points were not recognized. Maximal and minimal measured major strains are illustrated on the legend, and results of average major strains and thickness reduction (TR) through the longitudinal sections are in the Tab. 3 . In either case was measured major strain equal to zero. From approximately 200 measured values on the each sample were all values of major strain greater than value $0.007 \%$.

Tab. 3. Strain and thickness reduction of etched blanks

\begin{tabular}{|c|c|c|}
\hline Sample number & Average of MS [\%] & Average of TR [\%] \\
\hline 1 & 0.55 & 0.26 \\
\hline 2 & 0.91 & 0.15 \\
\hline 3 & 1.86 & 0.66 \\
\hline 4 & 0.59 & 0.42 \\
\hline 5 & 0.73 & 0.17 \\
\hline 6 & 1.22 & 0.09 \\
\hline 7 & 0.56 & 0.4 \\
\hline
\end{tabular}

Samples number 3 and 6 were scanned in insufficient quality, therefore for further experimental procedures were not used. Omitted places on the scans illustrated in the Fig. 5 and 6 may be caused by several factors as insufficiently clean surface, inequality of surface, errors during etching caused by long time of effects of electric current, imperfect photogrammetric detecting by cam- 
era, different light in the laboratory where the measurement takes place, different angles of taking photos etc. Software is defined in the way that diameter of etched point is equal to $1 \mathrm{~mm}$, but real diameter may be different and mentioned phenomenon may cause that points are smaller or larger than is defined and software it evaluate that blank was already loaded.

Next experimental procedure was strain measuring by two approaches. Differences between strain measuring with photo (PC) and video camera (VC) were discussed. Both of these methods have advantages and disadvantages. Advantage of using photo camera is possibility of measuring parts which are larger, since video camera is placed on the tripod and is difficult to scan larger parts from one place. Advantage of using video camera is that is more users friendly. Measured part is placed on the turntable, and photos are making by the simple computer commands. Blank were scanned by these two methods and results will be discussed. First, distribution of major strains and shape of blanks are in the Fig. 7.

Results are graphically illustrated in the Fig. 8 and values are evaluated in the Tab. 4. Shape of the blank is approximately equal. Minimal measured major strain differs by a very small amount. Difference between averages of major strain calculated using equation 1 in longitudinal sections is $20 \%$.

Tab. 4. Strain and thickness reduction of the blank

\begin{tabular}{|c|c|c|}
\hline Parameter & PC & VC \\
\hline Max. MS [\%] & 6.63 & 4.28 \\
\hline Min. MS [\%] & -1.88 & -1.89 \\
\hline Average of MS [\%] & 0.65 & 0.52 \\
\hline Standard deviation of MS [\%] & 0.85 & 0.74 \\
\hline Difference [\%] & \multicolumn{2}{|c|}{20} \\
\hline
\end{tabular}

From the results presented in the Tab. 4, the standard deviation and average of major strain is smaller in the case of video camera, it can be assumed that video camera has a smaller resolution and not whole areas of points were scanned accurately enough. Using of video camera is beneficial in the case of smaller parts, because is simpler and faster to measure strains. Photo camera is the only option in the case of measuring larger parts.
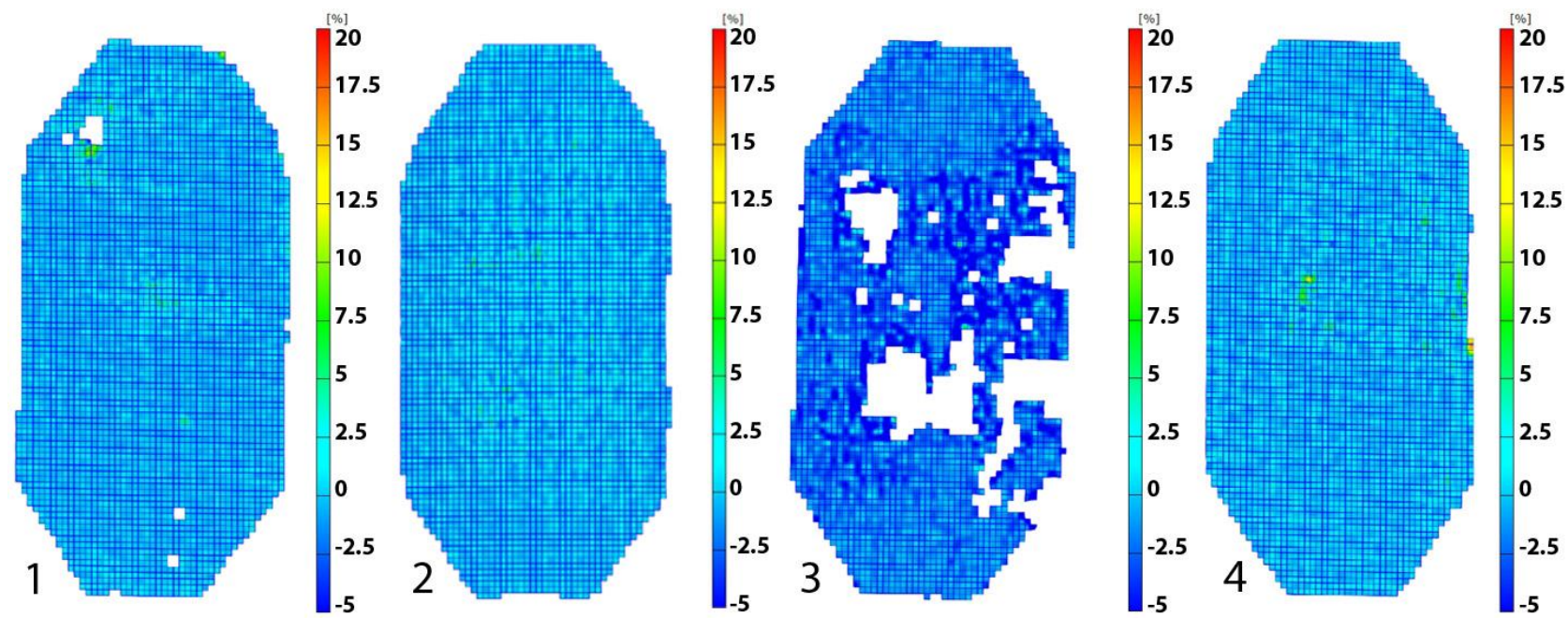

Fig. 6. Strain distribution on samples 1-4 from photogrammetric system. Data were measured using VC system
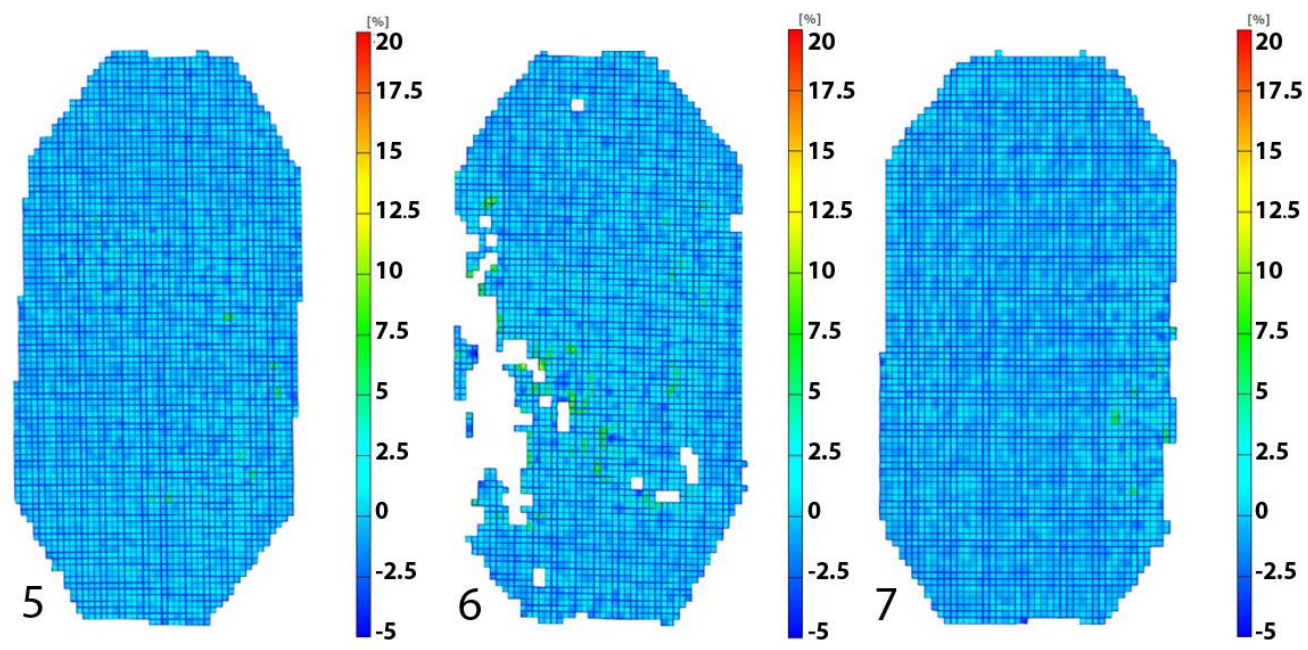

Fig. 7. Strain distribution on samples 5-7 from photogrammetric system. Data were measured using VC system 


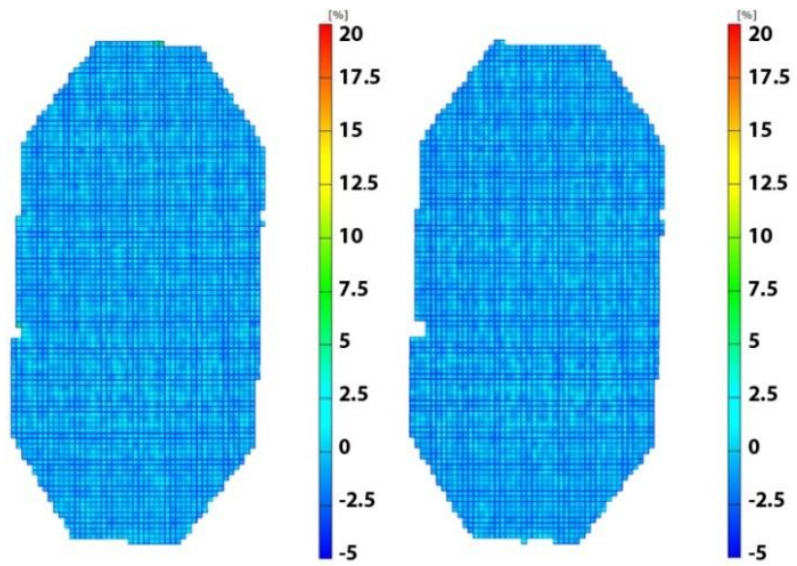

Fig. 8. Results of scanning using different sensing devices. On the left result of scanning using PC system, and on the right result of scanning using VC system
As in the previous cases, these differences will be discussed in the further chapter. Last experiment was focused to the comparison of photogrammetric measuring method, numerical simulation results and experimentally obtained results. After the evaluation of measurement illustrated in the Fig. 6 and 7, five blanks were used to the drawing process and GPS cover was drawn. Blanks number 3 and 6 were rejected, because if there has been visible significant problem during surface scanning in preproduction phase, it can be expected that there will be problem also during scanning in the post-production phase. In order to compare results, five different drawing depths were selected from 16 to $20 \mathrm{~mm}$. Even though in previous experiments was as a comparison parameter selected major strain, thickness reduction is more suitable for inspecting final product of deep drawing process. Therefore in this comparison was chosen this parameter. In the Fig. 9 - Fig. 13 are illustrated results in the two sections which are highlighted in the Fig. 4. Section curve illustrated in the Fig. 9 - Fig. 13 was obtained from measuring in ARGUS. This curve was plotted in order to illustrate position of GPS cover wall in which thickness reduction was measured.
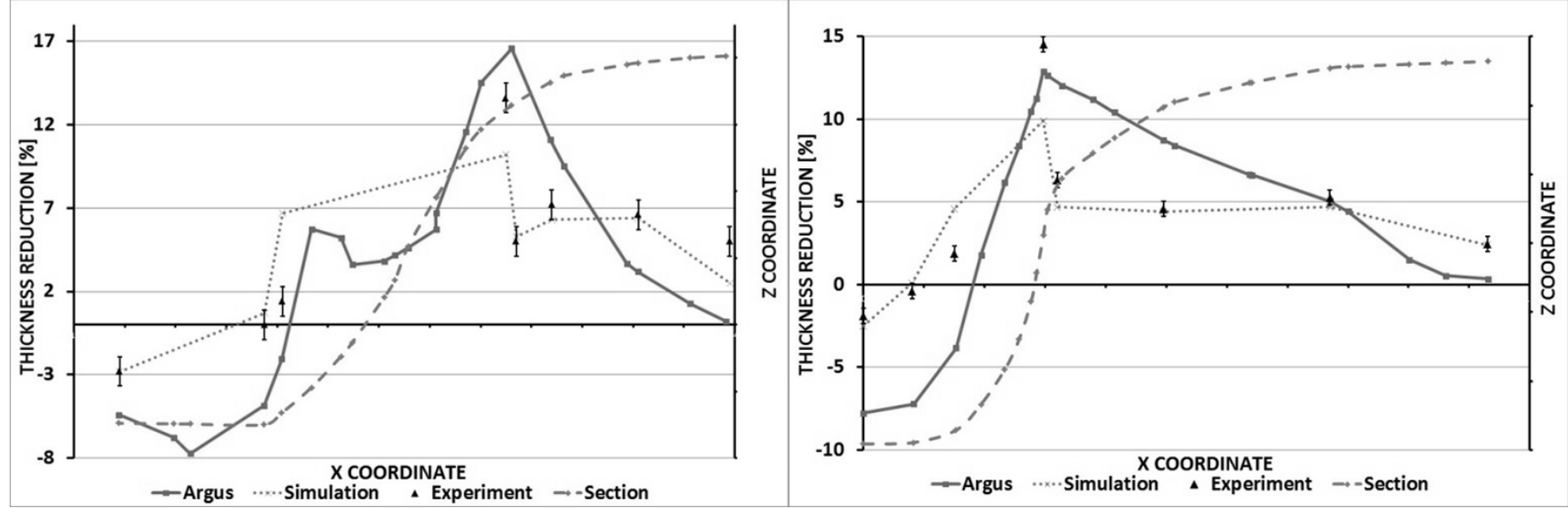

Fig. 9. Depth of drawn part equal to $16 \mathrm{~mm}$. Section $A$ on the left, section $B$ on the right
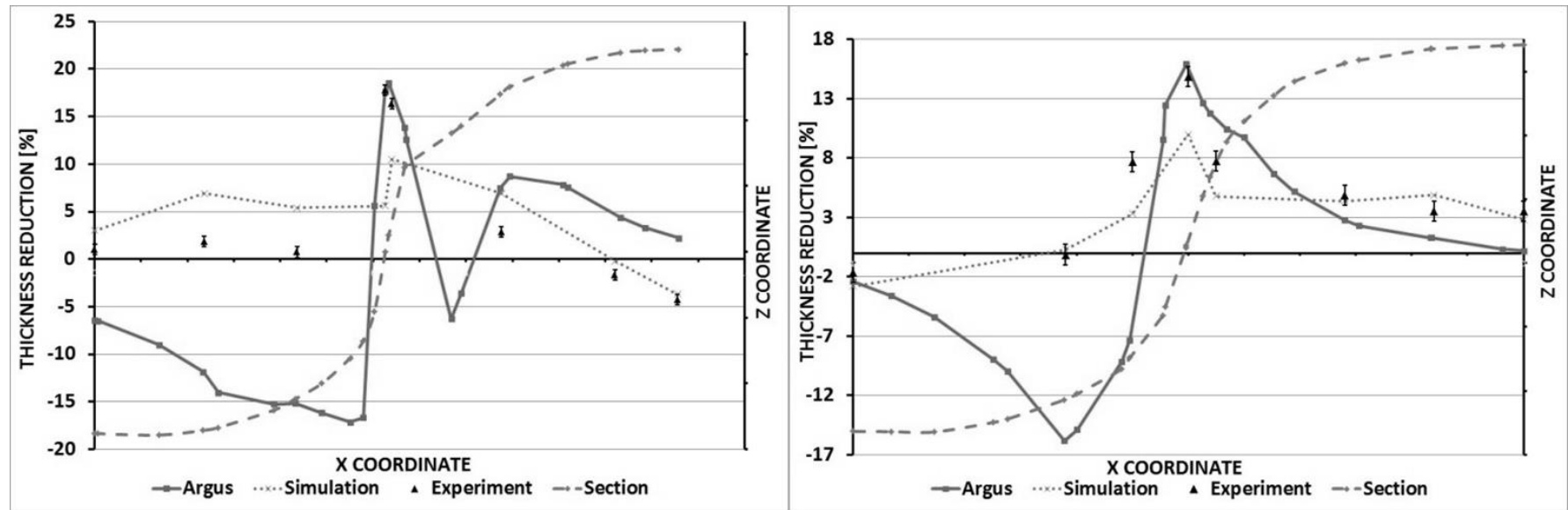

Fig. 10. Depth of drawn part equal to $17 \mathrm{~mm}$. Section $A$ on the left, section $B$ on the right 


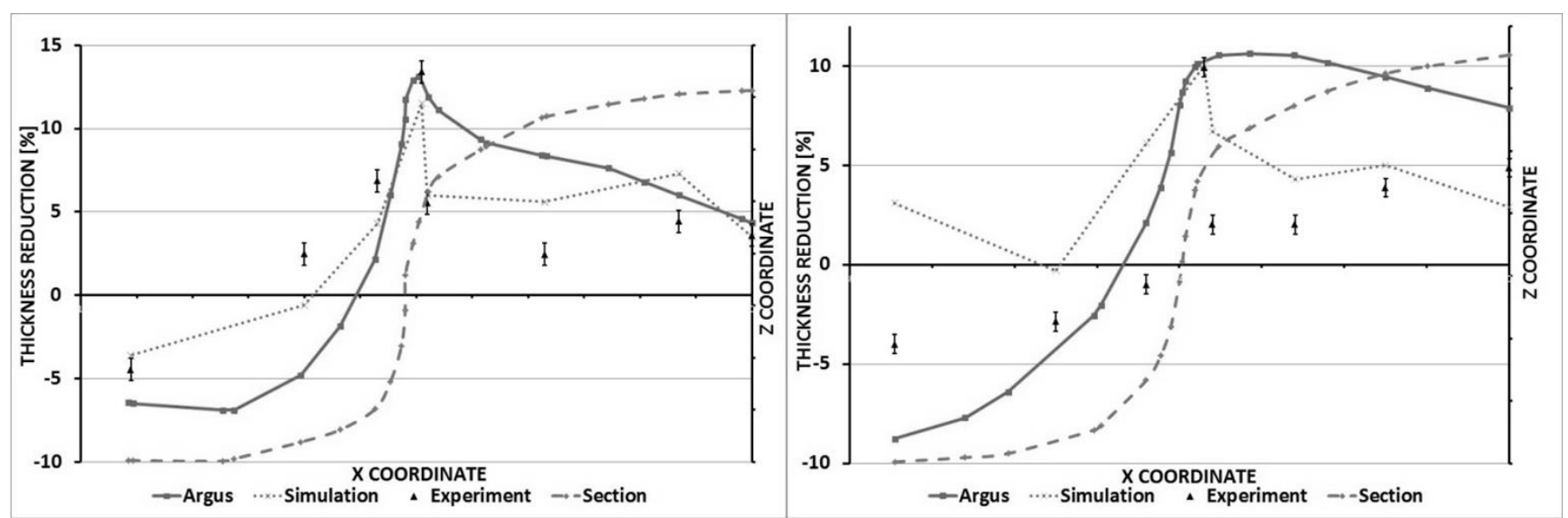

Fig. 11. Depth of drawn part equal to $18 \mathrm{~mm}$. Section $A$ on the left, section $B$ on the right
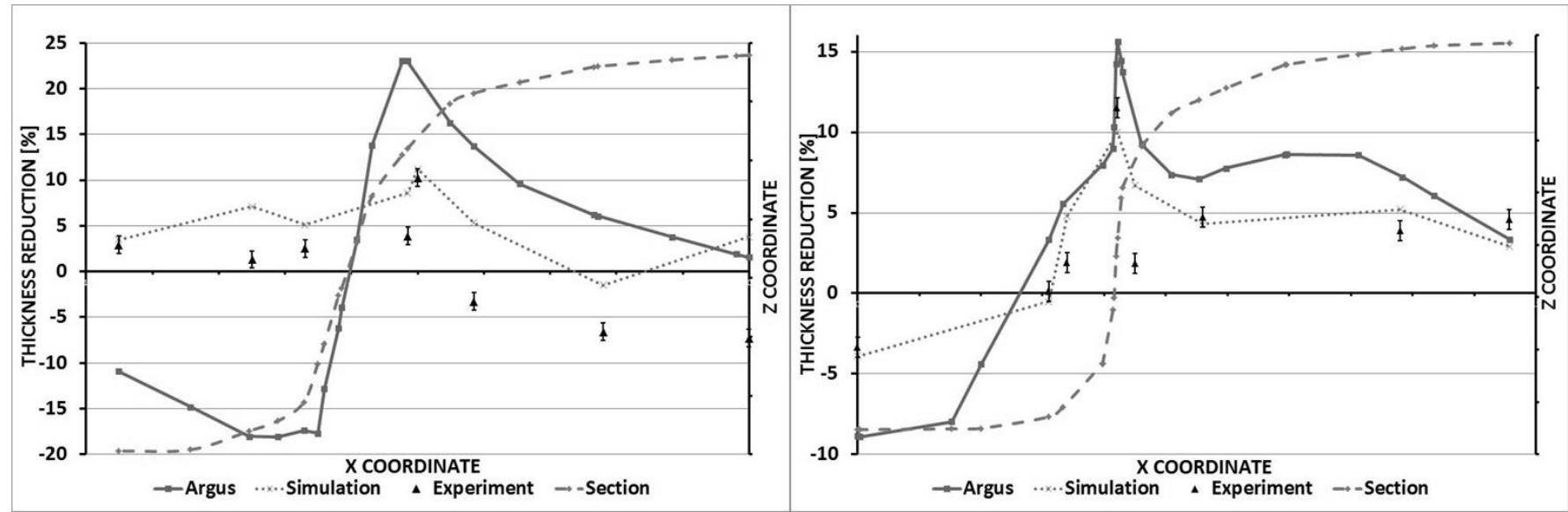

Fig. 12. Depth of drawn part equal to $19 \mathrm{~mm}$. Section $A$ on the left, section $B$ on the right
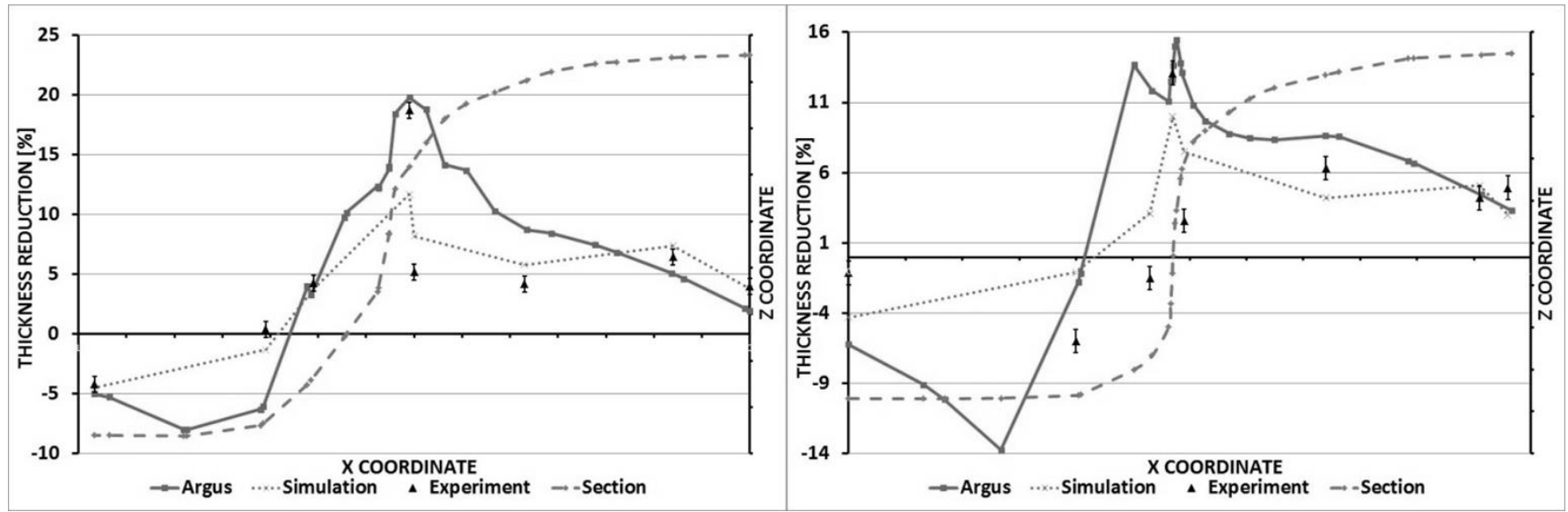

Fig. 13. Depth of drawn part equal to $20 \mathrm{~mm}$. Section $A$ on the left, section $B$ on the right

Results shown in the Fig. 9, for depth $16 \mathrm{~mm}$ are result of 8 experimental measuring, numerical simulation and photogrammetric method. In case of experimental measuring, measurement uncertainty was computed in every single point. In this case, numerical simulation was more accurate, because there was observed a greater overlap with experimental measuring. In case where drawing depth was set to $17 \mathrm{~mm}$, numerical simulation and photogrammetric scanning had a different course of results. As was illustrated in the Fig. 10, trend of the course is copied a greater in case of numerical simulation. In case, illustrated in the Fig. 11, where drawing depth was set to $18 \mathrm{~mm}$, numerical simulation and photogrammetric scanning had approximately the same distribution of thickness reduction. However, in the case of section $B$, in the first point, there was a great difference, because while numerical simulation computed that there was a positive thickness reduction, in the case of photogrammetric measuring there was measured negative thickness reduction what is corresponding with experimental measurement. Result of experiment, where 
drawing depth was set to $19 \mathrm{~mm}$ is shown in the Fig. 12. As from this graph implies, numerical simulation was more accurate in comparison to experimentally obtained values. The most critical local places were overestimated by ARGUS, what may not cause problems in technical practice. In the last drawing depth illustrated in the Fig. 13, as well as in the previous case, numerical simulation was more accurate. However, numerical simulation underestimated the value of thickness reduction in the most critical area. This may cause a problems in the production, or problems with quality of final product. From Fig. 9 -Fig. 13 implies that thickness reduction for greater drawing depth is not growing uniformly. It was caused by the reason that for every drawing depth was used new blank.

\section{CONCLUSIONS}

In this paper, two progressive methods of formability analysis were compared. It was proved, that there is difference between measured values of strain using photogrammetric $5 \mathrm{M}$ and $12 \mathrm{M}$ camera. It was also proved that anti-reflexive spray influence amount of measured strain. It was found that photogrammetric system does not provide acceptable accuracy in the measurement of certain areas of draw piece. There were observed great sensitivity of different factors to the measured values. Among these factors in pre-production phase it can be included the time of etching, an appropriate electrolyte, etching process parameters, different type of measuring grid, quality of sheet surface and others. In post-production phase it is type of used camera, application of developer, interpolation parameters, different lighting conditions, angles of camera view, number of captured pictures, etc.

Numerical simulation of process was performed in order to compare results with photogrammetric system. It was found that results of numerical simulation corresponded with experimentally obtained data greater than photogrammetric system. Results of numerical simulation can be more accurate either by better material description and material models considering Bauschinger effect, apparent Young's modulus, etc. or sophisticated computing algorithms. There still exist areas for continued development in the case of photogrammetric measuring and numerical simulation.

\section{REFERENCES}

1. Fracz W., Stachowicz F., Pieja T. (2013), Aspect of verification and numerical optimization of sheet metal and numerical simulations process using the photogrammetric system, Acta Metallurgica Slovaca, 19, 51-59.

2. Goellner M et al. (2010), Photogrammetric measurement of initial tooth displacement under tensile force, Medical Engineering \& Physics, 32, 883-888.

3. Griesbach B et al. (2010), Validation of sheet metal materials by forming analysis with automatic ARGUS measurement cell, International conference for integration of optical metrology in industry and research, Braunschweig, Germany.

4. Kruse F., Wendland B. (2010), Determination of draping characteristics of carbon glassfiber textiles using Argus, International conference for integration of oprical metrology in industry and research, Braunschweig, Germany.

5. Slota J., Jurčišin M. (2012), Experimental and numerical analysis of the deep drawing process using optical measuring system, Zeszyty Naukowe Politechniki Rzeszowskiej, 84-4, 37-45.

6. Ambriško L., Pešek L. (2011), Determination the crack growth resistance of automotive steel sheets, Chemické listy, 105, 767-768.

7. Hlebová S., Pešek L., Kandra T. (2011), Comparison of determination characteristics of the steel sheet in local and global area by the static loading using videoextensometry, Chemické listy, 105, 577-579.

8. Mihaliková M., Ambriško L., Pešek L. (2011), Videoextensometric measuring of deformation process in automotive steel at two strain rate levels, Kovové materiály, 49, 137-141.

9. ARGUS USER GUIDE. (2011), http://www.gom.com/.

10. Cover story: Focus on CAD CAM and simulation. (2001), Parametric die faces in one hour, International sheet metal review.

11. Schmidt A., Kunibert G.S. (2004), Design of adaptive finite element software, The finite element toolbox, Bremen: University of Bremen.

This contribution is the result of the projects implementation: Centre for research of control of technical, environmental and human risks for permanent development of production and products in mechanical engineering (ITMS: 26220120060) supported by the R\&D Operational Programme funded by the ERDF and VEGA 1/0396/11. 